\title{
STUDI KOMPARASI HASIL BELAJAR SISWA ANTARA MODEL PEMBELAJARAN KOOPERATIF TIPE TGT DENGAN TIPE TSTS PADA MATERI INTERAKSI MAKHLUK HIDUP DENGAN LINGKUNGAN KELAS VII DI SMP NEGERI 11 BATAM
}

\author{
Fenny Agustina $^{1}$, Rahmi $^{1}$, Susanto $^{2}$ \\ 1. Dosen Program Studi Pendidikan Biologi FKIP Universitas Riau Kepulauan \\ 2. Alumni Program Studi Pendidikan Biologi FKIP Universitas Riau Kepulauan
}

\begin{abstract}
This observational population is student braze VII SMP Negeri 11 Batam school years 2013 / 2014 consists 12 classes. By use of tech simple random is sampling utilized three classes as sample. Class is with model TGT'S learning brazes VII 2, Class is with model TSTS'S learning brazes VII 4, and control class by use of discourse learning model which is class VII 12. Acquired observational data by use of instrument essays to usufruct studying as essays executed double helix objektif after learning process is finished. analisis's stipubting quiz did by normality quiz and homogeneity quiz. Normality quiz by use of quiz chi square. Of that count result data gets normal distribution. Homogeneity quiz usufructs to study utilizes quiz Barlett, gotten big appreciative or $f_{\text {computing }}=571,600$ and $f_{\text {table }}=1,98$ on signifikan's level $\alpha=0,05$ since $f$ computing $>F$ table therefore samples drd variant be homogeneous. Drawned out into hypothesis quiz by use of quiz analisis variance (anova). Of hypothesis result is gotten $f$ computing = 3892,485 and that result is greater of $f$ table $=3,07$ with signifikan's level $\alpha=0,05$. So acquired hypothesis answer is refuse HO at a swoop accepts Ha. So concluded that deep observational it exists komparasi result studies student among model kooperatif's learning type TGT with type TSTS on living thing interaction material with environmentally brazes VII at SMP Country 11 Batam T.A. 2013 / 2014
\end{abstract}

Key word : Comparison, TGT, TSTS

\section{PENDAHULUAN}

Pembaharuan pendidikan harus dilakukan untuk meningkatkan kualitas pendidikan Nasional, sehingga diharapkan dapat meningkatkan harkat, martabat manusia Indonesia. Salah satu upaya yang dapat dilakukan untuk meningkatkan kualitas pendidikan Indonesia adalah dengan cara merubah paradigma pembelajaran, dari pembelajaran yang berpusat pada guru (teacher centered) ke arah pembelajaran yang berpusat pada siswa (student centered). Teacher centered adalah suatu metode pembelajaran di mana guru yang lebih mendominasi kelas (Nurhadi, 2004 dalam Yusuf, 2013).

Peningkatan kualitas sumber daya manusia merupakan salah satu penekanan dari tujuan pendidikan. Seperti yang tertuang dalam UU No 20 tahun 2003 tentang tujuan pendidikan 
nasional Bab II Pasal 3 yang berbunyi, "Pendidikan nasional bertujuan mengembangkan dan membentuk watak serta peradaban bangsa yang bermartabat dalam rangka mencerdaskan bangsa, bertujuan untuk berkembangnya potensi peserta didik agar menjadi manusia yang beriman, dan bertaqwa kepada Tuhan Yang Maha Esa, berakhlak mulia, sehat, berilmu, kreatif, mandiri, serta menjadi warga negera yang demokratif dan bertanggung jawab".

Dari uraian latar belakang disampaikan dapat kita identifikasi masalah sebagai berikut :

1. Kurangnya partisipasi siswa terhadap pelajaran Biologi sehingga kegiatan hanya berpusat pada guru.

2. Siswa merasa jenuh dalam pembelajaran yang monoton.

3. Masih ada siswa yang mendapatkan nilai di bawah KKM.

4. Tipe TGT dan TSTS belum pernah digunakan Di SMP Negeri 11 Batam

\section{METODE PENELITIAN}

Kata komparasi (comparation), yaitu perbandingan. Makna dari kata tersebut menunjukkan bahwa dalam penelitian ini peneliti bermaksud mengadakan perbandingan kondisi yang ada di dua tempat, apakah kedua kondisi tersebut sama, atau ada perbedaan, dan kalau ada perbedaan, kondisi di tempat mana yang lebih baik (Arikunto, 2010).

Terdapat dua model komparasi, yaitu komparasi antara dua sampel dan komparasi antara lebih dari dua sampel yang sering disebut komparasi k sampel. Selanjutnya setiap model komparasi sampel dibagi menjadi dua jenis yaitu sampel yang berkorelasi dan sampel yang tidak berkorelasi disebut dengan sampel independen (Sugiyono, 2011).

\subsection{Desain Penelitian}

Penelitian ini merupakan penelitian dengan hipotesis komparatif (perbandingan). Hal ini sesuai dengan pandapat Sugiyono (2011) "hipotesis komparatif adalah pernyataan yang menunjukan dugaan nilai dalam satu variabel atau lebih pada sampel yang berbeda". Pada penelitian ini, subyek penelitian yaitu siswa kelas VII SMP Negeri 11 Batam.

\section{Variabel Penelitian}

Dalam penelitian komparasi ada dua variabel, yaitu variabel bebas dan variabel terikat

a. Variabel bebas (independent) merupakan variabel yang mempengaruhi atau yang menjadi sebab perubahan atau timbulnya variabel terikat atau variabel bebas (X). Dalam penelitian ini variabel bebas yaitu kelas dengan pembelajaran TGT dan TSTS.

b. Variabel terikat (dependent) yaitu variabel yang dipengaruhi atau yang menjadi akibat, karena adanya variabel bebas. Variabel terikat (Y) dalam penelitian ini adalah hasil belajar Biologi

\section{Data Penelitian}

a. Jenis Data

Tes merupakan salah satu alat untuk melakukan pengukuran, yaitu alat untuk mengumpulkan informasi karakteristik suatu subyek. Karakteristik objek dapat berupa 
keterampilan, pengetahuan, sikap, minat, maupun bakat, baik yang dimiliki individu maupun kelompok (Widoyoko, 2012).

b. Sumber Data

Sumber data penelitian ini merupakan data primer karena sumber data yang langsung memberikan data kepada pengumpul data, yang berupa hasil pembelajaran yang berbentuk tes prestasi (achievement test). Menurut Widoyoko (2012) tes prestasi yang digunakan untuk mengukur pencapaian maupun kompetensi seseorang setelah mempelajari sesuatu. Tes prestasi diberikan setelah orang yang dimaksud telah mempelajari sesuatu hal sesuai dengan yang akan diteskan.

\subsection{Populasi dan Sampel}

Menurut Sugiyono (2012), Populasi adalah wilayah generalisasi yang terdiri atas: obyek atau subyek yang mempunyai kualitas dan karakteristik tertentu yang ditetapkan oleh peneliti untuk dipelajari dan kemudian ditarik kesimpulan.

Jadi populasi bukan hanya orang, tetapi juga obyek dan benda-benda alam yang lain. Populasi juga bukan sekedar jumlah yang ada obyek atau subyek yang dipelajari, tetapi meliputi seluruh sifat yang dimiliki oleh subyek atau obyek. Berdasarkan defenisi di atas, maka dalam penelitian ini menetapkan populasi adalah seluruh siswa kelas VII di SMP Negeri 11 Batam tahun pelajaran 2013/2014. Yang berjumlah 507 siswa dan terbagi ke dalam 12 rombongan belajar.

Sampel pada penelitian ini adalah kelas VII 2 (TGT) dan Kelas VII 4 (TSTS) di SMP Negeri 11 Batam tahun pelajaran 2013/2014. Pengambilan Sampel akan menggunakan teori Probabilitas dengan teknik cluster random sampling.

\subsection{Prosedur Penelitian}

Pada penelitian ini terdiri dari empat tahap yaitu, pada tahap pertama akan dilakukan perizinan, observasi dan pembuatan perangkat pembelajaran. Pada tahap kedua akan dilakukan perlakuan tarhadap sampel, yaitu peneratapan tipe TGT dan TSTS. Pada tahap ketiga dilakukan tahap pengumpulan data. Dan pada tahap terakhir pengolahan data yang diperoleh dengan dilakukannya posttest pada sampel. Kemudian dilanjutkan analisis data menggunakan uji t.

\subsection{Instrumen Penelitian}

Tes yang digunakan dalam penelitian ini adalah tes pilihan ganda (multiple choice test) dimana setiap butir soalnya memliki jumlah alternatif jawaban lebih dari satu. Jumlah instrument sebanyak dua puluh lima butir soal yang telah divalidasi.

\section{Uji Validitas}

Sugiyono (2011 : 348) mengatakan bahwa, "Hasil penelitian yang valid bila terdapat kesamaan antara data yang terkumpul dengan data yang sesungguhnya terjadi pada obyek yang diteliti". Instrumen yang valid berarti alat ukur yang digunakan untuk mendapatkan data (mengukur) itu valid. 
Data yang kita berikan harus valid, untuk mengujinya kita gunakan rumus product moment.

Rumus Product Moment :

Dimana :

$$
\mathrm{r}_{\mathrm{xy}}=\frac{\mathrm{n} \sum \mathrm{x}_{\mathrm{i}} \mathrm{y}_{\mathrm{i}}-\left(\sum \mathrm{x}_{\mathrm{i}}\right)\left(\sum \mathrm{y}_{\mathrm{i}}\right)}{\sqrt{\left[\mathrm{n} \sum \mathrm{x}_{\mathrm{i}}{ }^{2}-\left(\sum \mathrm{x}_{\mathrm{i}}\right)^{2}\right]\left[\mathrm{n} \sum \mathrm{y}_{\mathrm{i}}{ }^{2}-\left(\sum \mathrm{y}_{\mathrm{i}}\right)^{2}\right]}} \quad \text { (Sugiyono, 2011:228) }
$$

$\mathrm{r}_{\mathrm{xy}} \quad=$ koefisien antara variabel $\mathrm{X}$ dan variabel $\mathrm{Y}$

$\mathrm{n} \quad=$ jumlah responden

$\sum \mathrm{x}_{\mathrm{i}}^{2}=$ jumlah kuadrat dari nilai butir soal

$\sum \mathrm{y}_{\mathrm{i}}{ }^{2}=$ jumlah kuadrat dari y (nilai total)

$\left(\Sigma y_{\mathrm{i}}\right)^{2}=$ Kuadrat dari jumlah soal yang benar dijawab oleh setiap siswa

$\left(\Sigma \mathrm{x}_{\mathrm{i}}\right)^{2}=$ Kuadrat dari jumlah responden yang menjawab benar pada setiap Soal

\section{Uji Reliabilitas}

Instrumen tes dikatakan dapat dipercaya (reliable) jika memberikan hasil yang tetap (konsisten) apabila diteskan berkali-kali (Widoyoko, 2012:157).

Untuk uji reliabilitas menggunakan KR 20, karena menggunakan instrumen penelitian berbentuk pilihan ganda yaitu benar mempunyai nilai 1 dan salah mempunyai nilai 0 (Sugiyono, 2011:360). Sebelum menghitung pengujian reliabilitas maka dihitung terlebih dahulu varian totalnya dengan rumus sebagai berikut :

Dimana :

$$
\mathrm{S}_{\mathrm{t}}^{2}=\frac{\mathrm{x}^{2}}{\mathrm{n}} \longrightarrow \mathrm{X}_{\mathrm{t}}{ }^{2}=\sum \mathrm{X}_{\mathrm{t}}{ }^{2}-\frac{\left(\sum \mathrm{X}_{\mathrm{t}}\right)^{2}}{\mathrm{n}} \quad \text { (Sugiyono, 2011) }
$$

$$
\begin{array}{ll}
\mathrm{S}_{\mathrm{t}^{2}} & =\text { Varian total } \\
\mathrm{n} & =\text { Jumlah responden } \\
\mathrm{x} & =\text { Jumlah soal yang benar dijawab oleh masing-masing responden }
\end{array}
$$

Setelah dapat varian total instrumen, kemudian dapat dilakukan dengan rumus KR 20 (Kuder Richardson) :

Dimana :

$$
\mathrm{r}_{\mathrm{i}}=\frac{\mathrm{k}}{(\mathrm{k}-1)}\left\{\frac{\mathrm{st}^{2}-\sum \mathrm{p}_{\mathrm{q}} \mathrm{q}_{i}}{\mathrm{~s}_{\mathrm{t}}{ }^{2}}\right\} \quad \text { (Sugiyono, 2011) }
$$

$$
\begin{array}{ll}
\mathrm{r}_{\mathrm{i}} & =\text { Reliabilitas tes } \\
\mathrm{k} & =\text { Jumlah item dalam instrumen } \\
\mathrm{p} & =\text { Proporsi subyek yang menjawab item dengan benar } \\
\mathrm{q} & =\text { Proporsi subyek yang menjawab item dengan salah }(\mathrm{q}=1-\mathrm{p}) \\
\sum_{p q} & =\text { Jumlah hasil perkalian antara } \mathrm{p} \text { dan } \mathrm{q} \\
\mathrm{St}^{2} & =\text { Varian total }
\end{array}
$$

\section{Uji Normalitas}

Uji normalitas dilakukan untuk mengetahui normal atau tidaknya distribusi data yang menjadi syarat untuk menentukan jenis statistik apa yang dipakai dalam analisis lebih lanjut. Uji normalitas yang penulis gunakan adalah dengan menggunakan uji chi kuadrat $\left(\chi^{2}\right)$ dan sebagai langkah-langkah dalam menghitung normalitas dengan menggunakan rumus chi kuadrat. 
Pengujian homogenitas digunakan uji Bartlett karena dalam penelitian ini ada tiga varians. Dalam uji hipotesis digunakan pengujian hipotesis dengan analisis varians kerena berkenaan dengan perbedaan dua mean atau lebi. Indeks perbedaan menggunakan varians melalui $\mathrm{F}$ rasio. Unsur utama dalam analisis varians adalah variansi antar kelompok dan dalam kelompok, Dalam menghitung F rasio, Variansi antar kelompok ditempatkan sebagai pembilang sedangkan variansi dalam kelompok sebagai penyebut. nilai $\mathrm{F}$ rasio yang diperoleh kemudian di bandingkan denngan Ftabel pada taraf nyata dan derajat bebas tertentu.

\section{HASIL DAN PEMBAHASAN}

Penelitian terlebih dahulu melakukan uji coba instrumen untuk mendapatkan data validitas, indeks kesukaran, daya pembeda dan reliabilitas. Sebelum instrumen di uji cobakan pada dua kelas eksperimen dan satu kelas kontrol maka instrumen diuji cobakan terlebih dahulu guna mendapatkan instrumen yang valid/baik. Validitas butir soal dilaksanakan di kelas VII ${ }_{1}$ SMP Negeri 11 Batam, dimana jumlah siswa terdiri dari 42 siswa. Validitas instrumen dihitung dengan menggunakan rumus Point Biserial, dimana $n=42$ dan taraf signifikan $5 \%(0,05)$, maka nilai t tabel Point Biserial adalah 0,301.

Sesuai dengan hasil uji coba instrumen sebanyak 50 butir soal diperoleh 31 butir soal yang dinyatakan valid dan 19 soal dinyatakan tidak valid, soal yang tidak valid tidak diikutsertakan dalam perhitungan indeks kesukaran dan daya pembeda. Berdasarkan hasil perhitungan indeks kesukaran dari jumlah butir soal yang valid yaitu 31 butir soal, kesemuanya memiliki nilai interpretasi dalam kategori sedang, dengan tingkat reliabilits Sangat baik kerena memiliki indeks nilai 0,94. Kemudian dilakukan penghitungan nilai indeks kesukaran maka di peroleh 25 butir soal sesuai dengan kebutuhan penelitian.

Sebagai seorang guru kita harus mampu membuat kondisi belajar yang menyenangkan dengan banyak model pembelajaran yang telah banyak dikembangkan oleh para ahli pendidikan. Penentuan jenis model pembelajaran juga harus di sesuaikan dengan tingkatan pendidikannya. sehingga kita tidak akan kesulitan dalam menerapkan model pembelajaran yang kita pilih. Dengan begitu guru diharapkan mampu mendorong siswa dalam meningkatkan prestasi belajar.

Hasil penelitian ini diperoleh dari hasil posttest pada dua kelas eksperimen dan satu kelas kontrol. Pada kelas dua eksperimen kelas pertama diberikan model pembelajaran dengan tipe Teams Games Tournaments, dan satu kelas lagi diberikan model pembelajaran dengan tipe Two Stay Two Stray, sedangkan pada kelas kontrol diberikan dengan model ceramah. Penelitian ini bertuujuan untuk melihat komparasi antara kelas dengan model pembelajaran tipe Teams Games Tournaments dengan kelas dengan pembelajaran tipe Two Stay Two Stray. Untuk mengumpulkan data hasil belajar, peneliti menggunakan tes dengan pilihan jawaban sebanyak 25 butir soal serta diberikan tes setelah materi disampaikan.

Dari hasil yang diperoleh oleh peneliti, serta diukur dengan KKM pelajaran Biologi di SMP Negeri 11 Batam, yaitu 76. maka dapat dilihat model pembelajaran tipe TGT memberikan dampak yang baik terhadap hasil belajar siswa. Selain dari itu hasil perhitungan analisis varians juga di ketahui bahwa $\mathrm{F}>$ taraf nyata $(3892,485>3,07)$. Uji hipotesis tersebut menunjukkan 
bahwa terdapat komparasi anatara tipe TGT dengan tipe TSTS pada materi interaksi makhluk hidup dengan lingkungan. Sekaligus menerima Ha dan menolak Ho. Hasil belajar yang diperoleh oleh peneliti menunjukkan kelas dengan menggunakan pembelajaran tipe TGT memiliki nilai yang baik. Dibandingkan dengan pembelajaran tipe TSTS maupun metode ceramah.

Penelitian di atas juga didukung dari penelitian Artanti, (2012) menyimpulkan bahwa pembelajaran tipe TGT pada pelajaran Biologi menunjukkan peningktan hasil belajar. Pada penelitian sebelumnya oleh windarti (2012) penerapan pembelajaran TGT memiliki kelebihan

1. lebih meningkatkan pencurahan waktu untuk tugas

2. Mengedapankan penerimaan terhadap perbedaan individu

3. Dengan waktu yang sedikut dapat menguasai materi secara mendalam

4. Proses pembelajaran berlangsung dengan keaktifan dari siswa

5. Mendidik siswa untuk berlatih bersosialisasi dengan orang lain

6. Motivasi lebih tinggi

7. Hasil belajar lebih baik

8. Meningkatkan kebaikan budi, kepekaan dan toleransi.

Adapun Kelebihan Pembelajaran TSTS menurut Yohanes (2013)

1. Dapat diterapkan pada semua kelas / tingkatan.

2. Lebih berorientasi pada keaktifan.

3. Siswa akan berani mengungkapkan pendapatnya.

4. Menambah kekompakan dan percaya diri siswa.

5. Kemampuan berbicara siswa dapat ditingkatkan.

6. Membantu meningkatkan minat dan prestasi belajar

Pada dasarnya sebagai guru kita harus mampu memilih model pembelajran yang tepat untuk digunakan dalam melakukan proses pembelajaran. Karena model pembelajaran merupakan unsur yang sangat penting dan mempengaruhi hasil belajar siswa. Jika guru mampu memilih model pembelajaran yang tepat dengan materi pelajaran, Hasil belajar siswa juga akan meningkat, begitu pula sebaliknya.

Adapun kendala dalam penelitian ini pada saat proses membagi siswa dalam kelompok-kelompok kecil serta saat mereka berdiskusi. Mereka sibuk dengan teman sebangku. Untuk kelas dengan pembelajaran TGT, terkendala dengan perputaran mereka saat mengambil bola untuk menentukan soal pada kota nomor. kemudian ada kelompok yang jumlahnya tidak sama sehingga harus ada yang maju dua kali, dan mereka tidak mau. Sedangkan kendala Pada kelas dengan pembelajaran TSTS, kurangnya kerja sama saat mereka harus menyelesaikan tugas diskusi, yang terjadi hanya anak-anak yang memeiliki kemampuan tinggi saja yang melakukan diskusi. Meskipun saat bertamu dan menerima tamu mereka bekerja sama dengan baik.

Berdasarkan uraian di atas, dapat disimpulkan bahwa penerapan pembelajaran TGT lebih baik dibandingkan dengan pembelajaran TSTS. Karena TGT memiliki unsur bermain dan berkompetisi. 


\section{KESIMPULAN DAN SARAN}

Berdasarkan analisis data diketahui bahwa hasil belajar Biologi siswa dengan pembelajaran tipe TGT lebih efektif dibandingkan hasil belajar siswa dengan pembelajaran tipe TSTS. Hal ini terlihat dari nilai rata-rata perhitungan yang telah dilakukan maka didapat nilai rata-rata dari kelas dengan Pembelajaran tipe TGT sebesar 74,42 dan nilai rata-rata dari kelas dengan pembelajaran tipe TSTS sebesar 70,59, maka hasil belajar siswa lebih efektif pada kelas dengan pembelajara tipe TGT. Sehingga ada Komparasi hasil belajar antara pembelajaran tipe TGT dengan pembelajaran tipe TSTS pada materi interaksi makhluk hidup dengan lingkungan kelas VII SMP Negeri 11 Batam Tahun pelajaran 2013/2014.

Berdasarkan hasil penelitian ini, maka penulis ingin memberikan saran-saran yang dapat digunakan sebagai bahan masukan yaitu :

1. Guru Mata Pelajaran Biologi hendaknya mulai mencoba menerapkan Model pembalajaran TGT dan TSTS dalam proses pembalajaran, Karena dengan menggunakan model pembelajaran ini akan menuntuk siswa agar lebih aktif sesuai dengan tuntutan kurikulum 2013.

2. Siswa hendaknya mempersiapkan diri dengan belajar terlebih dahulu sebelum mengikuti pembelajaran.

3. Model Pembelajaran TGT dan TSTS banyak memberikan kebebasan kepada siswa, dan terkadang kebebasan itu digunakan untuk bermain-main dan kurang disiplin, maka perlu kemampuan pengelolaan kelas yang baik oleh guru dalam proses pembelajaran.

4. Bagi peneliti selajutnya dapat memgkombinasikan model pembelajaran TGT dengan TSTS pada materi pokok yang berbeda.

5. Untuk mempertahankan dan meningkatkan rata-rata prestasi belajar Biologi siswa, hendaknya guru senantiasa memberikan pengarahan tentang cara belajar yang baik agar siswa dapat membentuk kebiasaan belajar yang baik.

\section{DAFTAR PUSTAKA}

Arikunto, S.,2010, Prosedur Penelitian Suatu Pendekatan Praktik, Rineke Cipta, Jakarta.

Artanti, N., 2012.Efektifitas Pembelajaran Kooperatif Tipe TGT Mata Pelajaran Ipa kelas V SD Imbas Gugus Lokantara Kecamatan Temanggung Kabupaten Temanggung Semester II Tahun Pelajaran 2011/2012. Skripsi, Universitas Kristen Satya kencana. Salatiga

Gunawan, H.I., 2012,Pengaruh Penggunaan Metode TSTS Dalam Pembelajaran Matematika terhadap hasil balajar siswa Kelas V SD Kecamatan Sidorejo Kota Salatiga Semester II Tahun Ajaran 2011/2012. Skripsi.Universitas Kristen Satya kencana. Salatiga

Huda, M., 2013. Cooperative Learning, Metode, Teknik, Struktur, dan Model Penerapan. Pustaka Pelajar, Yogyakarta.

Isjoni, 2013. Pembelajaran Kooperatif, Meningkatkan Kecerdasan Komunikasi Antar Peserta Didik. Pustaka Pelajar, Yogyakarta.

Latisma, DJ. 2011. Evaluasi Pendidikan.Universitas Negeri Padang. Padang.

Slavin, R.E., 2009. Cooperative Learning, Teori, Riset, dan Praktik. Nusa Media, Bandung.

Sudjana, 2010. Metode \& Teknik Pembelajaran Partisipatif. Falah Prodution. Bandung. 
Sudjana, N. 2009. Penelitian dan penilaian Pendidikan. Sinar Baru Algensindo. Bandung.

Sugiyono, 2011. Statistika Untuk Penelitian. Alfabeta. Bandung, , 2012. Metode Penelitian Pendidikan Pendekatan Kuantitatif, Kualitatif, dan R\&D. Alfabeta, Bandung.

Usman, H., 2012. Pengantar Statistika. Bumi aksara, Jakarta.

Widoyoko EP. 2012. Teknik Penyusunan Instrumen Penelitian. Pustaka Pelajar. Yogyakarta.

Windarti,I.2012.Penerapan Model pembelajaran Kooperatif Tipe TGT dengan Bantuan Media Pohon Pintar dapat Meningkatkan Hasil Belajar Matematika siswa Kelas 5 SD Negeri Gerlang Semester 1 Tahun pelajaran 2013/2014. Skripsi. Universitas Kristen Satya kencana. Salatiga.

Yusuf.2012. Penerapan Pembelajaran Kooperatif Model Two Stay Two Stray(TSTS) Untuk Meningkatkan Hasil Belajar Siswa pada Mata Diklat Kewirausahaan(Studi pada kelas X SMK Ardjuna 2 Malang).Jurnal. Universitas Negeri Malang. Email : Oecoep_88@yahoo.com 